\title{
The KLMY90 \# Asphalt and Its Mixture Performance Research for Gannan Area
}

\author{
Cheng-qin Chen ${ }^{1,2}$, Wei Zhang ${ }^{1,2}$, Xiao Zhang ${ }^{1}$ and Xiu-le Chen ${ }^{1}$ \\ ${ }^{1}$ Northwest Minzu University for Nationalities Lanzhou 730124, China \\ ${ }^{2}$ Key Laboratory of New Laboratory of New Building Materials and Building Energy-saving of Gansu Province Lanzhou 730030, China
}

\begin{abstract}
Asphalt pavement is widely used at home and abroad because of its advantages of comfortable driving, convenient maintenance, short construction period, etc. Asphalt becomes brittle and is cracked in winter. Gannan is located in the plateau, belonging to plateau climate, low year-round temperature, often wind and rain, day and night temperature difference, strong sunlight. Therefore, the asphalt was selected with high temperature stability and low temperature ductility. The KLMY90\# asphalt and its mixture were studied for the technical properties. The results showed: the content of saturates and aromatic components reduced at aging temperature; the saturated and aromatic content decreased at aging time; the saturated content decreased slowly than the content of aromatic content as the aging time decreasing; the dynamic stability increased with the asphalt-aggregate ratio; the asphalt mixture had superior performance, strong water resistance. The KLMY90\# asphalt and its mixture were more suitable for paving roads for Gannan.
\end{abstract}

\section{Introduction}

Asphalt is a dark brown complex mixture composed of hydrocarbons of different molecular weights and their non-metal derivatives; it is soluble in carbon disulfide[1]. Asphalt pavement has many advantages such as comfortable driving, convenient maintenance, short construction period, easy maintenance, and no reflective driving at night [2-6]. There are many factors that affect the road performance of asphalt and asphalt mixtures, such as the nature of raw materials, climatic conditions, and composition of grading [2,3]. Gannan is located at the edge of the Qinghai-Tibet Plateau; the landforms are complex and diverse; the differences in elevation are obvious[7,8]. There is a great difference in the climate everywhere, and the asphalt is easy to crack. Therefore, the high-index asphalt is selected such as 90\#, 110\#; their softening point is lower, and the low-temperature ductility is good. The Shell Company makes a research on asphalt mixture with $100 \#$ asphalt. The penetration rate of bitumen is reduced to $70 \mathrm{~mm}$ after experience mixing; the porosity is $3 \%$ to $12 \%$ after being laid on the road for 5 years [3]. The KLMY90\# matrix asphalt and its mixture were studied to be suitable for the climate in Gannan region, and the reference basis put forward for the construction of asphalt pavement in this area.

\subsection{KLMY90\# asphalt technical indexes}

The KLMY90 \# asphalt's main technical indicators were tested according to the reference [9]. The results were shown in Table 1.

\subsection{Aggregate and mineral powder}

Coarse aggregates were available in 9.5 to $19 \mathrm{~mm}$, and 4.75 to $9.5 \mathrm{~mm}$; the technical specifications were shown in Table 2. Fine aggregates with an apparent density of $2.667 \mathrm{~g} / \mathrm{cm}^{3}$ were selected. The technical specifications for ore powder and hydrated lime powder were shown in Table 3.

\section{The Four-component}

The chemical composition of KLMY90\# asphalt was studied by changing rule of the four components of aged asphalt, which was tested by the method [9]. The design was as follows: (1) The asphalt four-component content was tested at the aging time for 5 hours under $153^{\circ} \mathrm{C}$, $163^{\circ} \mathrm{C}$, and $173^{\circ} \mathrm{C}$ respectively; the results were shown in Table 4; (2) the asphalt four-component content was tested at the aging time for $163^{\circ} \mathrm{C}$ at $5 \mathrm{~h}, 10 \mathrm{~h}$ and $15 \mathrm{~h}$ respectively; the results were shown in Table 5.

\section{Raw material test method and its technical performance indexes}


Table 1. Technical Indexes Values of KLMY 90\# Asphalt.

\begin{tabular}{|c|c|c|c|c|}
\hline \multicolumn{2}{|c|}{ Items } & The original asphalt & Test standard & Test basis \\
\hline \multirow{3}{*}{ Penetration $(0.1 \mathrm{~mm}$} & 30 & 150.2 & - & \multirow{3}{*}{ T0604-2000 } \\
\hline & 25 & 99.5 & $80 \sim 100$ & \\
\hline & 15 & 44.6 & - & \\
\hline \multicolumn{2}{|c|}{ Ductility $\left(5 \mathrm{~cm} / \mathrm{min}, 10^{\circ} \mathrm{C}, \mathrm{cm}\right)$} & 35.5 & $\nless 20$ & T0605-1993 \\
\hline \multicolumn{2}{|c|}{ Ductility $\left(5 \mathrm{~cm} / \mathrm{min}, 15^{\circ} \mathrm{C}, \mathrm{cm}\right)$} & $>100$ & $\nless 100$ & - \\
\hline \multicolumn{2}{|c|}{ Softening point $\left({ }^{\circ} \mathrm{C}\right)$} & 47.1 & $\nless 42$ & T0606-2000 \\
\hline \multicolumn{2}{|c|}{ Penetration index PI } & 0.753 & $-1.8 \sim+1.0$ & T0604-2000 \\
\hline \multicolumn{2}{|c|}{$\operatorname{Density}\left(15^{\circ} \mathrm{C}\right)$} & 0.990 & Actual measurement & T0603-1993 \\
\hline \multirow{3}{*}{ RTFOT $\left(163^{\circ} \mathrm{C}, 85 \mathrm{~min}\right)$} & & 0.4 & $-0.8 \sim 0.8$ & \multirow{3}{*}{ T0610-1993 } \\
\hline & ratio $(\%)$ & 69.02 & $\nless 54$ & \\
\hline & $\left.10^{\circ} \mathrm{C}\right), \mathrm{cm}$ & 8.13 & $\nless 6$ & \\
\hline
\end{tabular}

Table 2. Coarse aggregate technical indicators.

\begin{tabular}{|c|c|c|c|c|c|}
\hline \multicolumn{2}{|l|}{ Items } & Unit & Results & standard & Test basis \\
\hline \multicolumn{2}{|c|}{ Aggregate abrasion value } & $\%$ & 17.5 & $\ngtr 35$ & T0317-2005 \\
\hline \multicolumn{2}{|c|}{ Aggregate crushing value } & $\%$ & 23.6 & $\ngtr 30$ & T0316-2005 \\
\hline \multirow{2}{*}{ Specific absorption of aggregate } & $9.5 \sim 16 \mathrm{~mm}$ & \multirow{2}{*}{$\%$} & 0.686 & $\ngtr 3.0$ & \multirow{2}{*}{ T0304-2005 } \\
\hline & $4.75 \sim 9.5 \mathrm{~mm}$ & & 1.172 & $\ngtr 3.0$ & \\
\hline Needle flake particle concentration & Mixture & $\%$ & 13.4 & $\ngtr 20$ & T0312-2005 \\
\hline And asphalt adhesion(boiled method) & The original asphalt & Level & 2 & - & T0616-1993 \\
\hline \multirow{2}{*}{ Aggregate volume relative density } & $9.5 \sim 16 \mathrm{~mm}$ & \multirow{2}{*}{ - } & 2.620 & - & \multirow{2}{*}{ T0304-2005 } \\
\hline & $4.75 \sim 9.5 \mathrm{~mm}$ & & 2.590 & - & \\
\hline \multirow{2}{*}{$\begin{array}{l}\text { All kinds of aggregate apparent } \\
\text { relative density }\end{array}$} & $9.5 \sim 16 \mathrm{~mm}$ & \multirow{2}{*}{ - } & 2.668 & $\nless 2.45$ & \multirow{2}{*}{ T0304-2005 } \\
\hline & $4.75 \sim 9.5 \mathrm{~mm}$ & & 2.671 & $\nless 2.45$ & \\
\hline
\end{tabular}

Table 3. The results of mineral powder and hydrated lime powder.

\begin{tabular}{|c|c|c|c|c|}
\hline \multicolumn{2}{|c|}{ Items } & Results & standard & Test basis \\
\hline \multirow{2}{*}{$\begin{array}{c}\text { Apparent relative } \\
\text { density }\end{array}$} & Mineral powder & 2.685 & $\nless 2.45$ & \multirow{2}{*}{ T0352-2000 } \\
\cline { 2 - 4 } & Hydrated lime powder & 2.305 & - & T0353-2000 \\
\hline \multicolumn{2}{|c|}{ Slag hydrophilicity coefficient } & 0.60 & $<1$ & \\
\hline
\end{tabular}

Table 4. The percentage of four components after bitumen changes with aging temperature.

\begin{tabular}{|c|c|c|c|c|c|}
\hline \multirow{2}{*}{ Items } & & & \multicolumn{3}{|c|}{ Aging time 5h, aging temperature $153^{\circ} \mathrm{C}, 163^{\circ} \mathrm{C}, 173^{\circ} \mathrm{C}$} \\
\cline { 3 - 6 } & Standard (\%) & Un-aged (\%) & \multicolumn{2}{|c|}{$163^{\circ} \mathrm{C}$} & $173^{\circ} \mathrm{C}$ \\
\hline Asphaltene & - & 2.79 & 3.40 & 3.63 & 4.69 \\
\hline Saturates & $12 \sim 27$ & 26.92 & 26.91 & 26.90 & 26.84 \\
\hline Aromatics & $21 \sim 47$ & 38.61 & 36.13 & 33.17 & 30.77 \\
\hline Colloids & $31 \sim 55$ & 31.39 & 32.45 & 34.56 & 36.05 \\
\hline
\end{tabular}


Table 5. The percentage of four components after bitumen changes with aging time.

\begin{tabular}{|c|c|c|c|c|c|}
\hline \multirow{2}{*}{ Items } & \multirow{2}{*}{ Standard (\%) } & \multirow{2}{*}{ Un-aged (\%) } & \multicolumn{3}{|c|}{ Aging temperature $163^{\circ} \mathrm{C}$, aging time 5h,10h,15h(\%) } \\
\cline { 4 - 6 } & & & $5 \mathrm{~h}$ & $10 \mathrm{~h}$ & $15 \mathrm{~h}$ \\
\hline Asphaltene & - & 2.79 & 3.63 & 3.88 & 4.00 \\
\hline Saturates & $12 \sim 27$ & 26.92 & 26.90 & 25.15 & 23.58 \\
\hline Aromatics & $21 \sim 47$ & 38.61 & 33.17 & 32.89 & 31.36 \\
\hline Colloids & $31 \sim 55$ & 31.39 & 34.56 & 36.47 & 39.11 \\
\hline
\end{tabular}

From Table 4: the content of asphaltenes and colloids increased with the increase of aging temperature at the aging time of $5 \mathrm{~h}$; the asphaltene content change is not obviously, but the colloids content changed greatly with the aging temperature. The content of saturates and aromatic components gradually reduced with the increase of aging temperature. The decrease of aromatic content was faster than that of saturated content.

From Table 5: the bitumen did not change at the aging temperature $\left(163^{\circ} \mathrm{C}\right)$; the asphaltene content and the gum content increased with the aging time changing; and the increase degree for the colloid content was greater than that of the asphaltene content. The saturated content and aromatic content decreased with the increase of aging time; the content of saturated content decreased more slowly than the content of aromatic content as the aging time decreasing; the saturated components of asphalt and the content of aromatic components were oxidized in the aging process of asphalt; and the effects of ultraviolet rays were converted into asphaltenes and colloids, thereby reducing the performance of asphalt.

\section{Mixture ratio design method}

\subsection{Mineral mix design}

The design of the mineral composition was made according to the reference [10] for the AC-16. The composition of the gradation of the mineral materials was determined after adjustment (seen in Table 6).

\subsection{Mixture composition design}

The asphalt mixture Marshall test was carried out to determine the optimum oil consumption [9]. The results were shown in Table 7.

Table 6. Composition Calculation of the AC-16 Mineral Mixture

\begin{tabular}{|c|c|c|c|c|c|c|c|c|}
\hline \multirow{3}{*}{$\begin{array}{l}\text { Screen } \\
\text { size } \\
(\mathrm{mm})\end{array}$} & \multicolumn{6}{|c|}{ The original grading $(\%)$} & \multirow{2}{*}{\begin{tabular}{|c|}
$\begin{array}{c}\text { Synthetic grading } \\
(\%)\end{array}$ \\
-
\end{tabular}} & \multirow{2}{*}{\begin{tabular}{|c|} 
Specification \\
recommended range (\%) \\
-
\end{tabular}} \\
\hline & $\begin{array}{c}9.5 \sim 16 \mathrm{~mm} \\
\text { Gravel }\end{array}$ & $\begin{array}{c}4.75 \sim 9.5 \mathrm{~mm} \\
\text { Gravel }\end{array}$ & \begin{tabular}{|c|}
$0 \sim 5 \mathrm{~mm}$ \\
Aggregate \\
chips \\
\end{tabular} & $\begin{array}{c}0 \sim 5 \mathrm{~mm} \\
\text { Sand }\end{array}$ & $\begin{array}{l}\text { Mineral } \\
\text { powder }\end{array}$ & $\begin{array}{l}\text { Slaked } \\
\text { lime }\end{array}$ & & \\
\hline & 34 & 25 & 16 & 19 & 4 & 2 & 100 & \\
\hline 19.0 & 100 & 100.00 & 100.00 & 100.00 & 100.00 & 100.00 & 100.00 & 100 \\
\hline 16.0 & 77.73 & 100.00 & 100.00 & 100.00 & 100.00 & 100.00 & 92.43 & $90-100$ \\
\hline 13.2 & 45.60 & 100.00 & 100.00 & 100.00 & 100.00 & 100.00 & 81.50 & $76-92$ \\
\hline 9.5 & 5.71 & 96.80 & 100.00 & 100.00 & 100.00 & 100.00 & 67.14 & $60-80$ \\
\hline 4.75 & 0.17 & 17.61 & 96.64 & 99.86 & 100.00 & 100.00 & 44.90 & $34-62$ \\
\hline 2.36 & 0.00 & 1.50 & 76.97 & 92.26 & 100.00 & 100.00 & 36.22 & $20-48$ \\
\hline 1.18 & 0.00 & 0.00 & 57.65 & 60.50 & 100.00 & 100.00 & 26.72 & $13-36$ \\
\hline 0.6 & 0.00 & 0.00 & 44.78 & 32.98 & 100.00 & 100.00 & 19.43 & $9-26$ \\
\hline 0.3 & 0.00 & 0.00 & 30.04 & 10.51 & 99.65 & 100.00 & 12.79 & $7-18$ \\
\hline 0.15 & 0.00 & 0.00 & 17.75 & 3.88 & 98.95 & 97.80 & 9.49 & $5-14$ \\
\hline 0.075 & 0.00 & 0.00 & 6.20 & 1.46 & 80.90 & 82.00 & 6.14 & $4-8$ \\
\hline
\end{tabular}


Table 7. Marshall Mix Test Results.

\begin{tabular}{|c|c|c|c|c|c|}
\hline Asphalt-aggregate ratio & 4.0 & 4.5 & 5.0 & 5.5 & 6.0 \\
\hline Gross volume relative density & 2.284 & 2.316 & 2.331 & 2.370 & 2.381 \\
\hline Maximum theoretical relative density & 2.488 & 2.470 & 2.452 & 2.435 & 2.418 \\
\hline Porosity (\%) & 8.19 & 6.25 & 4.94 & 2.68 & 1.52 \\
\hline Mineral material gap rate (\%) & 16.5 & 15.8 & 15.6 & 14.6 & 14.6 \\
\hline Saturation (\%) & 50.5 & 60.5 & 68.4 & 81.7 & 89.6 \\
\hline Stability (kN) & 6.06 & 6.32 & 6.34 & 6.21 & 6.09 \\
\hline flow value $(0.1 \mathrm{~mm})$ & 26.5 & 30.5 & 32.6 & 34.8 & 37.6 \\
\hline
\end{tabular}

Table 7 showed: the relative density of the volume increased with the asphalt-aggregate ratio, but become smaller at 5.5. The ratio of voids and the change of voidage decreased; the gap rate of minerals decreased with the asphalt-aggregate ratio and unchanged at 5.5; the stability increased with the asphalt-aggregate ratio, but started to decrease at 5.0; the saturation and flow values increased with the asphalt-aggregate ratio. The optimum amount of asphalt was determined: $\mathrm{OAC}_{1}=5.029 \% ; \quad \mathrm{OAC}_{2}=(4.997 \%+5.226 \%) / 2=5.112 \%$; $\mathrm{OAC}=\left(\mathrm{OAC}_{1}+\mathrm{OAC}_{2}\right) / 2=5.070 \%$. The best asphalt-aggregate ratio was set at $5.1 \%$, and the optimum amount of bitumen was converted to $4.85 \%$. The final grading composition of minerals was that: $9.5 \sim 16 \mathrm{~mm}$ gravel $34 \%, 4.75 \sim 9.5 \mathrm{~mm}$ gravel $25 \%, 0 \sim 5 \mathrm{~mm}$ gravel $16 \%, 0 \sim 5 \mathrm{~mm}$ sand $19 \%$, mineral powder $4.0 \%$, slaked lime $2.0 \%$ The optimum asphalt-aggregate ratio is $5.1 \%$.

\section{The road Performance}

(1)High temperature stability: the experimental results were shown in Table 8 . Table 8 showed: the rut depth increased. The material surface had good performance, flexibility, and durability. The dynamic stability increased with the asphalt-aggregate ratio. In addition, the experimental data also showed that the temperature had the greatest impact on the asphalt mixture, and the frequency and speed were both greater. (2) Water stability: the sability was $6.29 \mathrm{kN}$ at $30 \mathrm{~min}$ of soaking; the sability was $6.12 \mathrm{kN}$ at $48 \mathrm{~h}$ of soaking. The residual stability was $97.38 \%$, which showed that the impact of water was relatively small, and the water resistance was relatively strong.

Table 8. Rutting experimental results.

\begin{tabular}{|c|c|c|c|c|c|}
\hline \multirow{2}{*}{ No. } & \multirow{2}{*}{ Test temperature } & \multicolumn{2}{|c|}{ Rut depth (mm) /(min) } & \multirow{2}{*}{$\begin{array}{c}\text { Dynamic stability } \\
(\text { time } / \mathrm{mm})\end{array}$} & \multirow{2}{*}{$\begin{array}{l}\text { Average } \\
\text { value(time } / \mathrm{mm})\end{array}$} \\
\hline & & 45 & 60 & & \\
\hline (1) & \multirow{3}{*}{$60^{\circ} \mathrm{C}$} & 1.984 & 2.264 & 2250.0 & \multirow{3}{*}{1974.9} \\
\hline (2) & & 2.473 & 2.822 & 1805.2 & \\
\hline (3) & & 2.419 & 2.756 & 1869.4 & \\
\hline
\end{tabular}

\section{Conclusions}

The content of saturates and aromatic components gradually reduced, the saturated and aromatic content decreased, and the saturated content decreased more slowly than the content of aromatic content as the aging time decreasing. The dynamic stability increased with the asphalt-aggregate ratio; the asphalt mixture was superior in performance and its ability to resist water intrusion was better; the water resistance was relatively strong. The KLMY90\# asphalt and its mixture were more suitable for paving roads in cold regions of Gannan.

\section{Acknowledgements}

The project funds are the professional project funds of the central university basic scientific research business expenses, the project number of which are 31920160086 and 31920150071; and the project fund also contains the Northwest Minzu University undergraduate research and innovation project, the project number of which is Z18003.

\section{References}

1. Shao-qiang Jia. Influence Factors and Improvement Measures of Asphalt Pavement Durability.Traffic world(2012).

2. Hong Pan. Applicability of Asphalt and Asphalt Mixtures. Chang'an University, master's thesis. (2016). 
3. Yan-li Li, Chao Wang, Fang-shu Bai. The influence of the air voids of asphalt mixture. Shanxi building. (2015)

4. Chang-gong Zhang. Research on the influence of percent air voids and percent air connected voids on the performance of asphalt mixtures. Chang'an University, master's thesis(2016)

5. Kun-zhi Zhong, Rong Luo, Xiang-yang Fan, etal. Effect of Air Voids on the Antirutting Performance of Water-immersed GRAVEL Asphalt Mixture. Journal of Wuhan university of technology (Transportation Science \& Engineering)(2016)

6. Xiao-ning ZHANG, Ying-mei YIN, Gui- lian ZOU. Viscoelastic Performance of Asphalt Mixture with
Different Void Contents. China Journal of Highway and Transport(2010)

7. Yaru WANG, Xueyan ZHAO, Qin ZHANG, etal. Farmers' climate change adaptation strategies in an ecologically. Vulnerable alpine region: A case of Gannan Plateau. Geographical research(2016)

8. Wen-hao WANG. Analysis of Climatic Condition of Gannan Alpine Grassland Based on 3S. Journal of animal husbandry and veterinary(2017)

9. E20-2011 Highway Engineering Asphalt and Asphalt Mixture Experimental Protocol.

10. JTG F40-2004 Technical Specification for Highway Asphalt Pavement Construction. 